\title{
Evaluation of NDVI Using SPOT-5 Satellite Data for Northern Ghana
}

\author{
Desmond Ofosu Anim (Corresponding author) \\ College of Environment, Hohai University \\ 1 Xikang Road, 210098 Nanjing, China
}

Tel: 86-158-9598-4009Ｅ-mail: desofosa@gmail.com

\author{
Amos Tiereyangn Kabo-bah \\ Green WaterHut \\ Box UP 913, KNUST, Ghana
}

Tel: 86-134-0414-0016_E-mail: kabo-bah@greenwaterhut.org

\author{
Philip Nti Nkrumah \\ College of Environment, Hohai University \\ 1 Xikang Road, 210098 Nanjing, China
}

Tel: 86-158-9598-2024Ｅ-mail: philiponti1209@yahoo.com

\author{
Raphinos Tackmore Murava \\ College of Water Conservancy and Hydropower, Hohai University \\ 1 Xikang Road, 210098 Nanjing, China \\ Tel: 86-134-0414-8637_E-mail: murreky@gmail.com
}

Received: April 3, 2013 Accepted: April 15, 2013

doi:10.5296/emsd.v2i1.3709

URL: http://dx.doi.org/10.5296/emsd.v2i1.3709

\begin{abstract}
Monitoring environment changes has become a necessity as a result of current environment
\end{abstract}


deteriorating due to human activities and climate change. However, in most developing countries like Ghana, acquiring information concerning the current condition and the dynamic changes of the environment for a rapid monitoring is difficult. A method to monitor the environmental condition in Northern Ghana by the way of the vegetation cover using the Normalized Difference Vegetation Index (NDVI) is proposed. The method involves the use of remotely sensed data based on the absorption, transmittance and reflectance of energy by the vegetation which is significantly correlated with the amount of green leaf biomass on ground. The accuracy of this indicator is assessed with other in-situ geographic data. The main aim was to assess whether the NDVI-time series extracted from SPOT-5 images may give reliable information to assess the environment herein vegetation or land cover in Northern Ghana where there is a current rapid environmental change. It is shown that the NDVI data gives some valuable information about the vegetation hence land cover in these areas. The measurement of the amount of greenness in different areas in Northern Ghana would be simple but an objective method to assist in regular evaluation of the environmental situation of an area. The study demonstrated that NDVI technique can be employed to evaluate the vegetation cover and hence monitor the environment. Consequently, this method can be applied for other areas in the country and will be useful as an effective tool for regularly monitoring to support and create environmental awareness about the vegetative changes.

Keywords: Northern Ghana, Vegetation indices, NDVI, SPOT- 5, DEM, Remote sensing

\section{Introduction}

Rapid environmental changes especially land use and land cover has become an important component in global change (Vitousek et al, 1997). Land-use pertained shifts is now seen as main driving force of biodiversity loss especially in tropical ecosystems (Anim et al, 2013).It has therefore become growingly necessary for countries to monitor their environment and overcome issues of environment deteriorating which normally leads to destruction of important ecosystem, loss of productive croplands and biodiversity. Environmental monitoring and thus planning and management of the environment are normally constrained by the unavailability of adequate data. The acquisition and update of information concerning the current condition and the dynamic changes of the environment in developing countries and the tropics such as Ghana is very difficult if not impossible in some instances. The utilization of remote sensing (RS) techniques for monitoring terrestrial ecosystem has become advantageous (Foody, 2002). RS techniques has become an important tool in environmental studies because it is able to give an objective, repeatable and cost effective information over large areas and can be empirically be referred to field data collected using traditional methods (Amiri and Tabatabaie, 2009). Commonly applied RS technique in environmental monitoring is vegetation monitoring and evaluation through vegetation indices which integrate reflectance measurements from the bands of the sensor ( Bannari et al, 1995; Thiam and Eastman, 2001). These vegetation indices are acquired from the use of satellite imagery from various sensors.

The development of vegetation indices from brightness values is based on the differential absorption, transmittance, and reflectance of energy by the vegetation in the red and 
near-inbared portions of the electromagnetic spectrum (Derring and Haas, 1980; Lyon and McCarthy, 1995; Jensen, 1996).

It has been shown over the years that the ratio of near-infrared MSS band 4 and red MSS band 2 is significantly correlated with the amount of the green leaf biomass (Tucker, 1979; Prince, 1991). Numerous vegetation indices have been formulated to make use of this difference. Basic techniques include subtraction of the near-infrared band and red band, division of near-infrared band by red band, and combinations of both that seek to normalize the response (Tucker, 1979; Lyon and George, 1979; Perry and Lautenschlager, 1984; Elvidge and Lyon, 1985; Price, 1992). However the most widely used is the Normalized Difference Vegetative Index (NDVI) (Rouse et al, 1974; Tucker et al, 1985; Panda et al., 2010).

Over the years, many researchers have successfully employed NDVI to monitor vegetation variations as a way of monitoring the environment globally especially in Africa (Tucker et al, 1985; Malo and Nicholson 1990; Schultz and Halpert 1993; Anyamba and Eastman 1996; Yang et al. 1997). This was therefore assumed sometimes to be a best substitute for areas where required data for the monitoring is scarce. Ghana, considered a developing country has seen rapid environmental changes due to urbanization and population which has put a lot of pressure on the environment especially in the Northern Ghana which is currently experiencing general environmental dynamics. Regrettably, available and updated data to monitor such changes is scares. Hence, a way to provide a regular quick assessment of the environmental situation is required. This study thus attempts to propose a simple but objective method to regularly evaluate the environmental situation. The understanding of the NDVI was considered an important input into the various large-scale models for modelling environmental and hydrologic changes. Unfortunately, this NDVI index has not been thoroughly evaluated in this region especially with the use of high resolution satellite imagery.

The main focus of the study is to investigate the use of NDVI as an indicator for assessing the environment by measuring the amount of greenness in different parts of Northern Ghana. This study thus provides baseline information about the various NDVI indices over the Northern Ghana.

\subsection{Vegetation Indices}

Vegetation indices have long been used in remote sensing for monitoring temporal changes associated with vegetation (Yacouba et al., 2009). Vegetation index are data obtained from multispectral data derived from the difference in absorption, transmittance and reflectance properties of vegetation in the red and near-infrared bands (Fung and Siu, 2000). Over the years, various researchers have calculated vegetation indices which include Perpendicular Vegetation Index (PIV), Ratio Vegetation Index (RVI), Normalized Difference Vegetation Index (NDVI), Soil Adjusted Vegetation Index (SAVI) and so on. These vegetative indices are each designed to emphasize a particular vegetative property but share almost the same kind of information (Perry and Lautenschlager, 1984). However, NDVI is generally proven as a good indicator of terrestrial vegetation growth or photosynthetic activities and is one of the most frequently used vegetation indices (Tucker et al 1985; Wang et al, 2003). NDVI is 
mathematically defined as:

$$
N D V I=\frac{N I R-R E D}{N I R+R E D}
$$

where RED and NIR are the visible red and near-infrared reflectance value respectively. The positive values indicates different types of vegetation classes, whereas near zero and negative values indicate non-vegetation classes, such as water, snow, built-up areas and barren land (Yacouba et al., 2009). The combination of its normalized difference formulations and use of the highest absorption and reflectance regions of chlorophyll have proved to be robust over a wide range of conditions. Hence, it is used in this study for the evaluation of the vegetation variation in Northern Ghana. March et al (1992) have also established that NDVI obtained from SPOT data was suitable for monitoring vegetation changes and dynamics.

\section{Study Area}

The study areas are located in Northern Ghana. It spreads between the latitude $9^{0}$ and 10 $30^{\prime} \mathrm{N}$ and longitudes $0^{\circ}$ to $230^{\prime}$ (Figure 1). They are located in the Guinea Savannah of the country. The Northern Ghana is made up of three regions namely Upper West (UWR), Upper East (UER) and Northern (NR) region. It has an approximate total land area of 97,700km2 and a total population of approximately 4.2M (Ghana Statistical Service, 2012). This part of Ghana is mostly seen to be poor and economically disadvantaged with a larger population relying on subsistence farming. The northern Ghana record two main seasons (wet and dry season). The wet season begins in May and lasts in October with a prolonged dry season between November and March (Braimoh and Vlek, 2004) with a mean annual rainfall between $800 \mathrm{~mm}$ and $1100 \mathrm{~mm}$. A significant portion of the Volta basin falls in the northern Ghana and is heavily drained by a number of important tributaries of the White Volta (Figure 1). However most of these rivers and streams are seasonal and dry up during the prolonged dry season. The natural vegetation is characterized by Guinea Savannah in the NR, grading into Sudan Savannah in the semi-arid region in the UER consisting of short trees of varying sizes and density growing over dispersed vast areas of perennial grassland shrubs. The soil type is characterized by the alluvial soils mainly at the major river valleys and drainage floors; reddish well-drained sandy loams on the Upper Voltanian sandstones, and moist sandy loams on slopes near valley bottoms (Braimoh and Vlek, 2004). Generally, the terrain is low lying or flat with larger areas of equal elevations with marginally undulating land of sandstone and mudstone with a characteristic layer of iron-stone at shallow depth. The relief features and soil texture in these areas generally foster water-logged conditions especially in the west of the White Volta during the wet season and draughty soils in the dry season. 


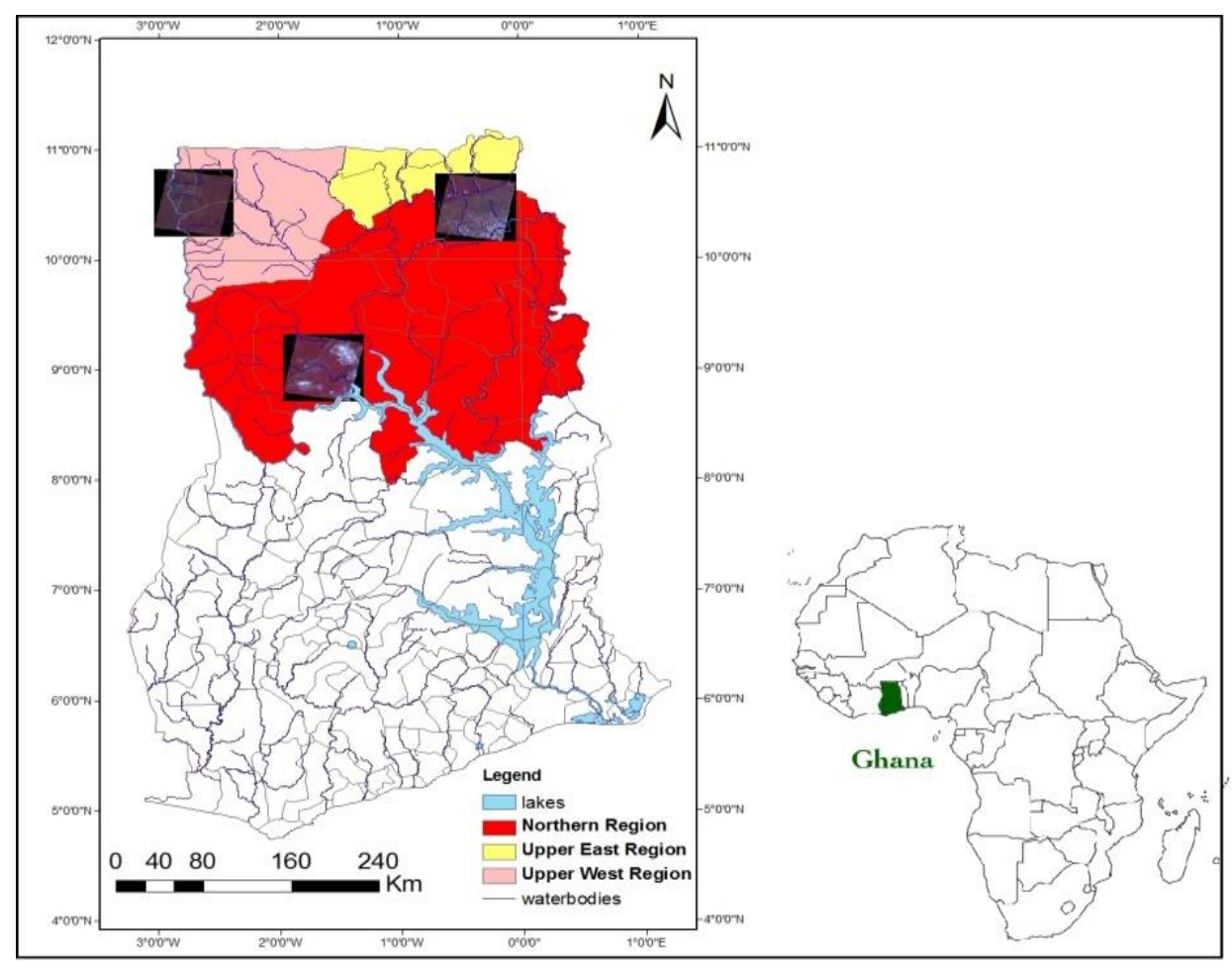

Figure 1. Map of Ghana showing the study areas

\section{Material and Methods}

\subsection{Data Sources}

\subsubsection{SPOT-5 data and Image processing}

SPOT 5 HRVR multispectral data sets were used in this study. They were obtained on 3 July 2010, 24 September 2010 and 30 October 2010. They were acquired during the wet season in Northern Ghana where vegetation growth begins to sprout starting from July which mark the early stages of the wet season to the peak stage (September) and ending in the month of the October. The dataset for July, September and October represented the UER, NR, and UWR of the Northern Ghana respectively (Figure 1). SPOT-5 scenes have a 10m-pixel resolution and 4 spectral bands: band 1 (0.50-0.59 $\mu \mathrm{m}$ : green), band $2(0.61-0.68 \mu \mathrm{m}$ : red), band $3(0.79-0.89$ $\mu \mathrm{m}$ : near infrared NIR) and band 4 (1.57 -1.75 $\mu \mathrm{m}$ : short-wave infrared SWIR). Table 1 shows the information about these three satellite images. The Second Simulation Satellite Signal in the Solar Spectrum Vector (6SV) (Vermote et al, 2006) was adapted to perform radiometric and atmospheric correction on the images. These atmospheric processes modify the solar radiance reflected by target considering the main atmospheric and scattering absorption effect (Vermote et al, 2006). Geometric corrections were also performed on the image using controlled points from a digital topographic map (Global Maps, USGS EROS). The NDVI was then calculated for each scene and NDVI maps produced which was use to analyze and classify the vegetation cover types and also study how vegetation type varies across Northern Ghana. Figure 2 gives the process method in this study. 


\section{Mll Macrothink

Table 1. SPOT-5 scenes extract parameters

\begin{tabular}{llll}
\hline Date of acquisition & 3 July 2010 & 24 Sept 2010 & 30 Oct 2010 \\
\hline Time & $10: 17: 05$ & $10: 18: 56$ & $10: 24: 52$ \\
Image Index & K057/J329 & K055/J332 & K052/J328 \\
Instrument & HRVIR 1 & HRVIR 2 & HRVIR 1 \\
\hline Orientation angle $\left(^{\circ}\right)$ & 8.6 & 8.6 & 8.7 \\
\hline Incidence angle $\left(^{\circ}\right)$ & R 10.4 & R 10.0 & R 5.6 \\
\hline Azimuth $\left(^{\circ}\right)$ & 60.4 & 109.1 & 137.5 \\
Sun elevation angle $\left(^{\circ}\right)$ & 61.3 & 63.5 & 56.9 \\
\hline
\end{tabular}

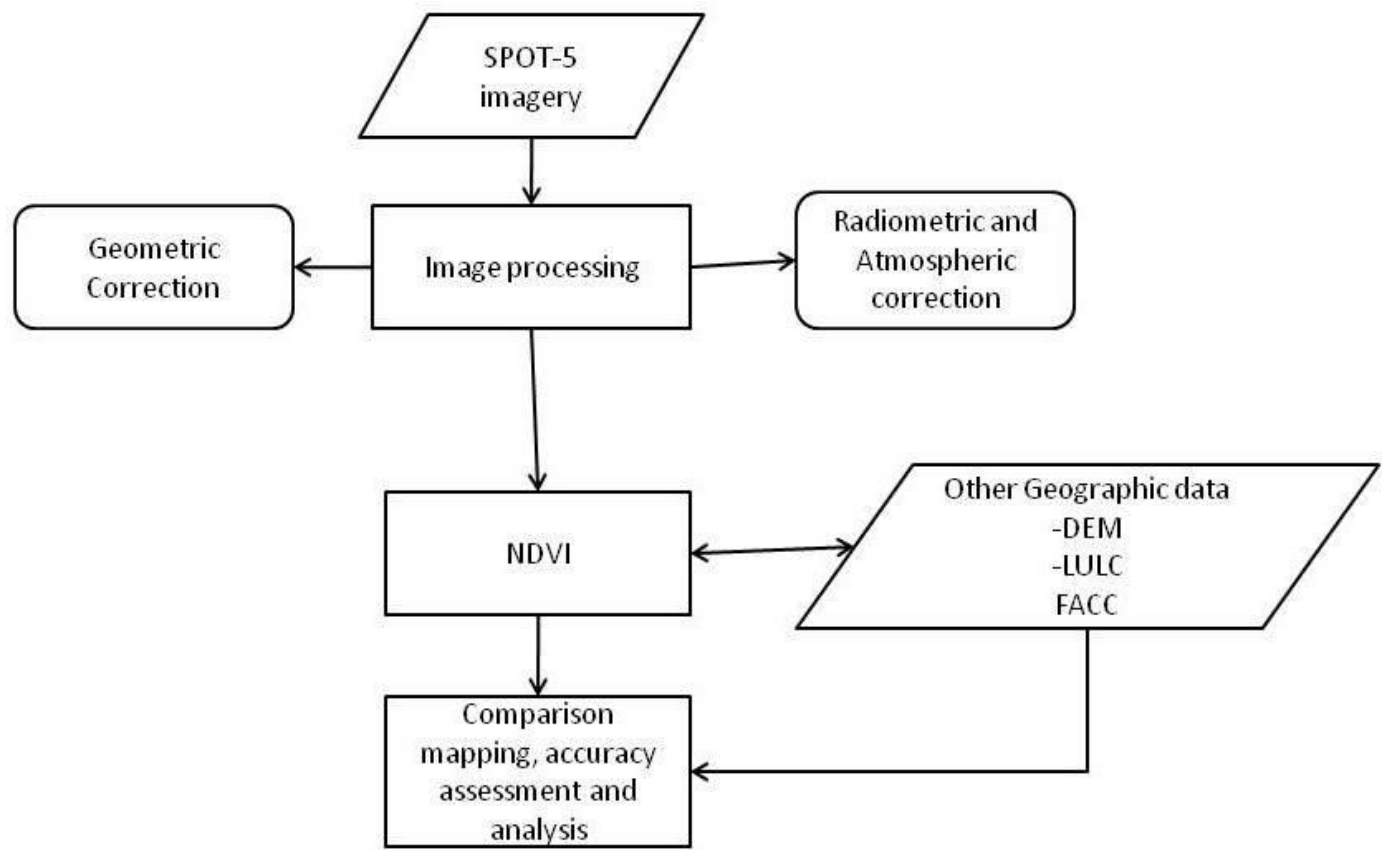

Figure 2. The process method in this study

\subsubsection{Other Data}

To aid the investigation and evaluation of the vegetation variation of the study area, other spatial data were collected and produced. A landuse/landcover map for the Northern Ghana (Global Maps, USGS EROS online database) was adapted to enable analyses of the vegetation variation. Also a Digital Elevation Model (DEM) was downloaded from CGIAR Consortuim for Spatial Information (CGIAR-CSI) online database to give a relief of the study area. The SRTM 90m DEM have a resolution of $90 \mathrm{~m}$ at the equator. This enabled the analyses of the relations between the NDVI and in situ relief of the areas and terrain-related attributes and features. A flow direction and accumulation map was also produced to give a drainage pattern of the study areas. By evaluating a DEM, the DEM hydro-processing tools in ILWIS were able to calculate flow accumulation. The FACC algorithm performs a cumulative count of the number of pixels that naturally drain into outlets based on the principle of D-8 flow algorithm performed as an operation in the DEM hydro-processing in ILWIS Open 


\section{Ml Macrothink}

(Maathuis and Wang, 2006). This will helped to explain the relations between the NDVI and the in situ water flow hydrology.

\subsection{NDVI}

The NDVI was calculated using equation 1. The NDVI values for the study areas in the Northern Ghana are in the ranges of -0.4 to 0.4 , where an increasing positive values show increasing green vegetation cover and negative values shows non-vegetated features like water bodies, waterlogged land, bare lands or clouds. These values were stratified in this study according to land cover categories. Table 2 shows the classification range in this study. The NDVI values shows almost identical trend of vegetation cover in Northern Ghana. With these areas having multiple drains coupled with an almost flat and less undulating terrain, the NDVI shows large areas depicting water or waterlogged areas. These phenomena could indicate that all the SPOT scenes were taken during the wet season. To carefully observed the vegetation cover variation across the study areas, the NDVI maps were divided into 9 regions (A-I) for each study area (Figure 3).

Table 2. Land features classification range in this study

\begin{tabular}{lll}
\hline $\begin{array}{l}\text { NDVI } \\
\text { values }\end{array}$ & $\begin{array}{l}\text { Land } \\
\text { Feature }\end{array}$ & Description \\
\hline $\mathbf{< - 0 . 1}$ & Water & $\begin{array}{l}\text { Areas covered with water such as rivers, streams, lakes and } \\
\text { waterlogged areas }\end{array}$ \\
$\mathbf{- 0 . 1 - 0 . 1 5}$ & Bare land & $\begin{array}{l}\text { Areas with no vegetation cover, degraded land and all unused area } \\
\text { or settlement areas }\end{array}$ \\
$\mathbf{0 . 1 5 - 0 . 2 5}$ & Cropland & $\begin{array}{l}\text { Planted and irrigated cropping, rain fed cropping and cultivated } \\
\text { areas. Areas covered mainly with grassland and herbaceous } \\
\text { vegetation with shrubs }\end{array}$ \\
& $\begin{array}{l}\text { Areas covered with tree crops, woody vegetation , shrubby plants } \\
\text { and other plants growing sparsely }\end{array}$ \\
0.25-0.32 & Open & $\begin{array}{l}\text { Areas with dense plants growing together, deciduous plants and } \\
\text { Savanna woodland }\end{array}$ \\
\hline
\end{tabular}

\subsection{Evaluating the Accuracy and Dependency of NDVI}

In this study, various data were obtained and compared with the results given by the NDVI. This was in an attempt to evaluate the measure of accuracy and reliability of the land cover condition predicted by the NDVI by examining the relations between each of the land monitoring datasets. The comparison and evaluation were between the NDVI and SRTM elevation range map (DEM), land cover and landform classification and flow accumulation map of the area. 


\section{$\triangle$ Macrothink}

\section{Results and Discussion}

\subsection{General Trend of NDVI}

It was found that, in the UER (Figure 3a), the NDVI values in region A, B and D are high (0.3-0.4) indicating denser vegetation cover. Similar behavior is observed at $\mathrm{H}$ and I but with NDVI values lower than that of A, B and D (i.e.0.15-0.25). Regions F and G shows low NDVI values (0-0.06) with $\mathrm{E}$ having the lowest $(\leq-0.1)$. This indicates land covers of bare land and water. Similarly, it was found in UWR (Figure $3 b$ ) that a greater portion of the study area was covered by grassland and cropland. Regions C, I, H shows high NDVI values (0.22-0.34) indicating denser vegetation. This is followed by region $\mathrm{A}, \mathrm{F}$ and $\mathrm{B}$ which shows slightly high NDVI values (0.14-0.2) showing less dense greener vegetation. Regions B, E, D have low NDVI values which indicate bare land and water (-0.08 -0.1). For NR (Figure 3c), a greater portion is covered by shrub land and open and deciduous forest. Region A, B and D has high NDVI values (0.25-0.35) with a greater portion of open and deciduous forest. Regions C, F and I have low NDVI values indicating bare lands and water areas. Regions E and G have a fairly high NDVI indicating less dense vegetation of grassland and cropland. NR also shows generally to a large extent bare land areas. This may be due to the fact that a greater portion of this study area is developed for settlement.

Generally, the NDVI shows Northern Ghana to have greater proportion of vegetation or land cover being Cropland followed by Open forest. Table 3 gives a descriptive statistics of the NDVI values for the various land feature categories.

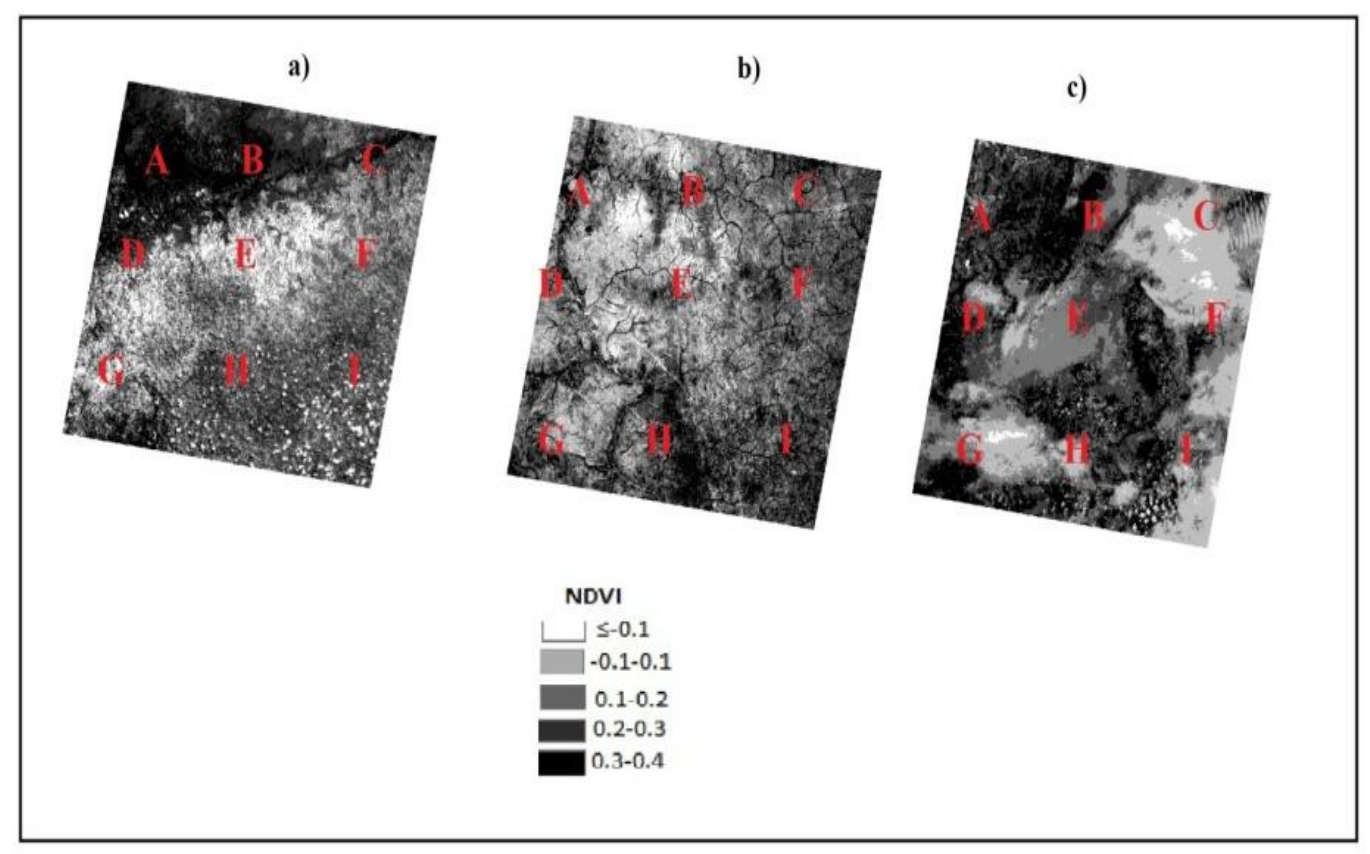

Figure 3. NDVI maps for the various study areas. a) UER b) UWR and c) NR 
Table 3. Descriptive statistics NDVI values for the various land features in all the study areas

\begin{tabular}{llllll}
\hline Land feature type & Min & Max & Mean & StDev & Total pixel no. \\
\hline Water & \multicolumn{5}{c}{ UER Study area NDVI values } \\
\hline Bare land & -0.223 & -0.100 & -0.131 & 0.03 & 28 \\
\hline Crop land & -0.100 & 0.150 & 0.012 & 0.05 & 7387676 \\
\hline Open forest & 0.150 & 0.250 & 0.150 & 0.03 & 22516247 \\
\hline Close forest & 0.250 & 0.320 & 0.240 & 0.03 & 6980434 \\
\hline Water & 0.320 & 0.400 & 0.321 & 0.02 & 579 \\
\hline Bare land & -0.302 & -0.100 & -0.144 & 0.044 & 223 \\
\hline Crop land & -0.100 & 0.150 & 0.007 & 0.055 & 6067038 \\
\hline Open forest & 0.150 & 0.250 & 0.149 & 0.029 & 28508180 \\
\hline Close forest & 0.250 & 0.320 & 0.238 & 0.025 & 1448453 \\
\hline Water & 0.320 & 0.466 & 0.343 & 0.043 & 32 \\
\hline Bare land & -0.408 & -0.100 & -0.149 & 0.058 & 106 \\
\hline Crop land & -0.100 & 0.150 & 0.017 & 0.051 & 1397056 \\
\hline Open forest & 0.150 & 0.250 & 0.149 & 0.029 & 2119596900 \\
\hline Close forest & 0.250 & 0.320 & 0.241 & 0.028 & 1419588700 \\
\hline & 0.320 & 0.400 & 0.321 & 0.023 & 371800 \\
\hline
\end{tabular}

4.2 Analysis of Relations between NDVI and Other Data

\subsubsection{NDVI and DEM}

The elevation maps were derived from the DEM (Figure 4). This was employed to evaluate and understand the relation and variation of NDVI with relief or topography. Furthermore, the elevation and the slope information from the DEM also helped as a commonsense rule to remove the interpolation of the presence or absence of certain feature classes in some elevation area. For instance, croplands or agricultural land in many tropical nations like Ghana are not expected to be located at higher elevations. These areas can thus be regarded as bare land. Variation between NDVI interpreted land features was established with the help of the elevation and slope information. This criterion was further established based on our prior field knowledge of the study areas. Table 4 gives the approximate maximum and minimum elevation and slope at the study areas from the DEM. Generally the DEM elevation and slope information shows wide areas of similar elevation which is very particular of Northern Ghana with almost wide flat terrain with sparsely undulating areas.

It was observed that in the UER, majority of the high NDVI values interpreted as open and/or closed forest were mainly found on elevation of $240 \mathrm{~m}$. Areas of NDVI values less than -0.1 are located in regions with low elevation (110-180 m) with some known water bodies. Other regions of elevation 270 - $350 \mathrm{~m}$ were found to have NDVI values below -0.1 indicating water. However these areas have no known water bodies. Thus, this could be classified as waterlogged areas (as well as flooded areas) since scene was taken at wet season. NDVI 
values of low positive values $(\leq 0.15-0.25)$ representing cropland and value close to zero $(\leq 0.1-0.15)$ also indicated bare land. These were found in the regions of $200-300 \mathrm{~m}$ elevation.

For the UWR study area (in accordance with the DEM), high NDVI values are in majority found in regions with 280-320 m elevation. NDVI values in the limit of $0.15-0.25$ were found in the regions with 250-280 m elevation. Also NDVI values less than -0.1 are in the region of low elevation (225-240 m) with known water bodies (rivers, streams). However, other areas with recorded low NDVI values $(<-0.1)$ were found in regions of 280-300 m with no known water body and hence classified as waterlogged due to wet season scenario.

In a similar manner, in NR study area, the NDVI values of 0.15-0.25 were frequently located at regions of $65-165 \mathrm{~m}$ elevation. High NDVI values $(0.3-0.4)$ were located at regions of $170-250 \mathrm{~m}$ elevation and also $260-330 \mathrm{~m}$. Also low NDVI values $(\leq-0.1)$ were at regions of $65-165 \mathrm{~m}$ and 200-230m respectively.

Table 4. Approximate maximum and minimum elevation and slope at the study areas from the DEM

\begin{tabular}{lllll}
\hline Study area & \multicolumn{4}{c}{ DEM } \\
\cline { 2 - 5 } & Elevation & \multicolumn{3}{c}{ Slope } \\
& Min & Max & Min & Max \\
Upper East Region (UER) & 225 & 460 & 0 & 90 \\
Upper West Region (UWR & 113 & 530 & 0 & 90 \\
Northern Region (NR) & 61 & 335 & 0 & 90 \\
\hline
\end{tabular}

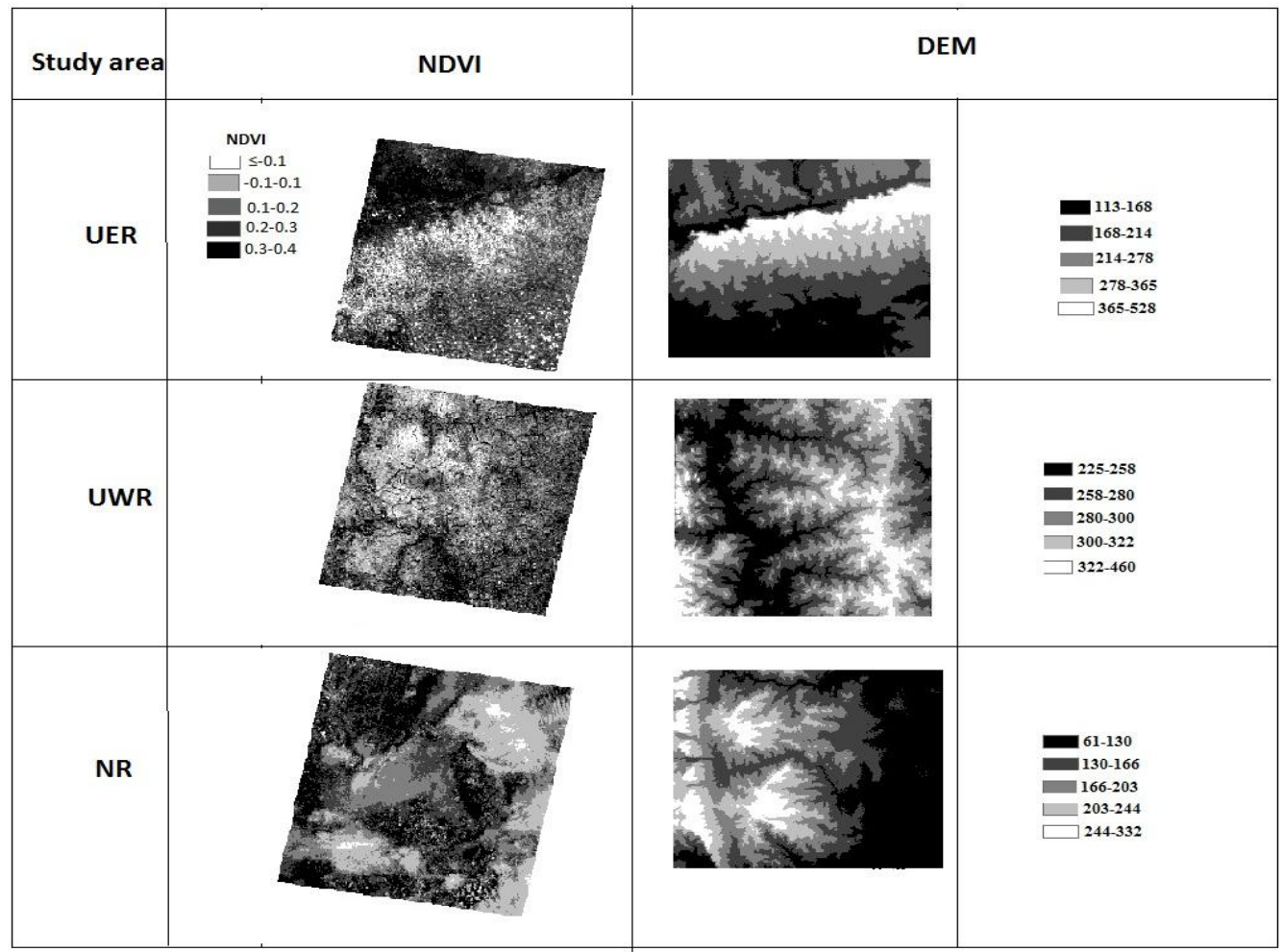

Figure 4. The derived elevation map (DEM) compared with the NDVI 


\subsubsection{NDVI and Landuse/Landcover Map}

The NDVI map was compared with a reference available Land use/ land cover map (LULC) (Figure 5). Analysis examined relations reported by the NDVI map as to the in-situ land cover category.

For the UER study area (Figure 5a), at regions A, B and D, the NDVI map reported a high NDVI values representing open or closed forest which corresponded to the LULC map. Regions $\mathrm{H}$ and I reported positive values indicating cropland and open forest which also matched with the LULC map. Regions F and G showed low NDVI values representing bare or degraded land or settlement area. However, the LU/LC map partly corresponded showing rather a greater portion of these regions being cropland. Region E indicates water on the NDVI map which in contrast to the LULC indicates cropland. This may be explained as the area being waterlogged due to wet season.

As rightly depicted by NDVI map in comparison to the LULC map, the UWR study area (Figure 5b) showed greater percentage covered by cropland. Regions C, I and H was predicted well by NDVI map indicating closed or open forest. Regions A, F, and B were also correctly predicted by NDVI map indicating crop or grassland. Regions B, E, and D showed low NDVI values which indicate bare land or water. In contrast, the LULC map shows a greater part of those regions being crop or grassland with little portion indicating bare land. Similarly, as rightly indicated by NDVI map compared to the LULC map, NR study area (Figure 5c) showed a greater portion covered by open or closed forest and bare land. Regions D and G correspond to the LULC map showing open forest and crop or grassland areas. However at regions B and $\mathrm{E}$ which were reported by the NDVI map as water were found to be crop or grassland.

In all, the NDVI could predict correctly the vegetation cover for most regions of the study areas. In contrast, it was observed that most areas (about 80\%) which were predicted to be water by NDVI map were actually found to be areas of crop or grassland and sometimes unused or bare land. This was hence attributed to the fact that all the scenes were taken in the wet season and perhaps those areas could have been flooded with water. This is a general case of Northern Ghana which experiences frequent flooding hence large areas covered with water (waterlogged) are recorded annually (Gyasi, 1995). This is due to the extended lowland terrains in these areas. This could also be attributed to the soil types in these areas. The most recognized soil type in Northern Ghana is Voltanian sandstones and clayey granites interspersed with Pyroclastic rocks (Nartey et al, 1997). These have better retention of precipitation and are easily waterlogged. Figure 6 shows the vegetation or land cover as given by NDVI values. 


\section{MInstitute Macrothink $^{\text {Int }}$}

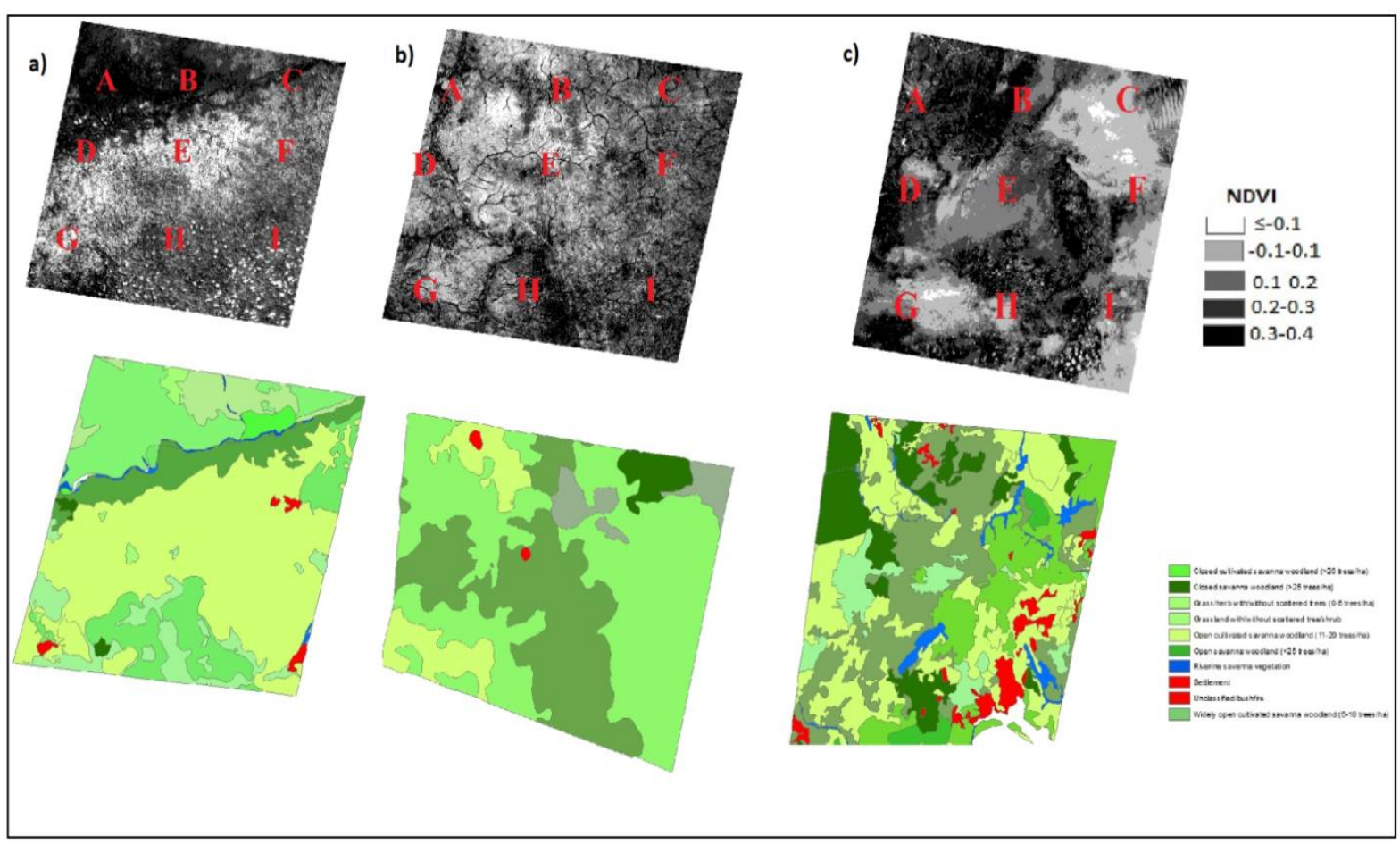

Figure 5. The NDVI map compared with a Land use/ land cover map

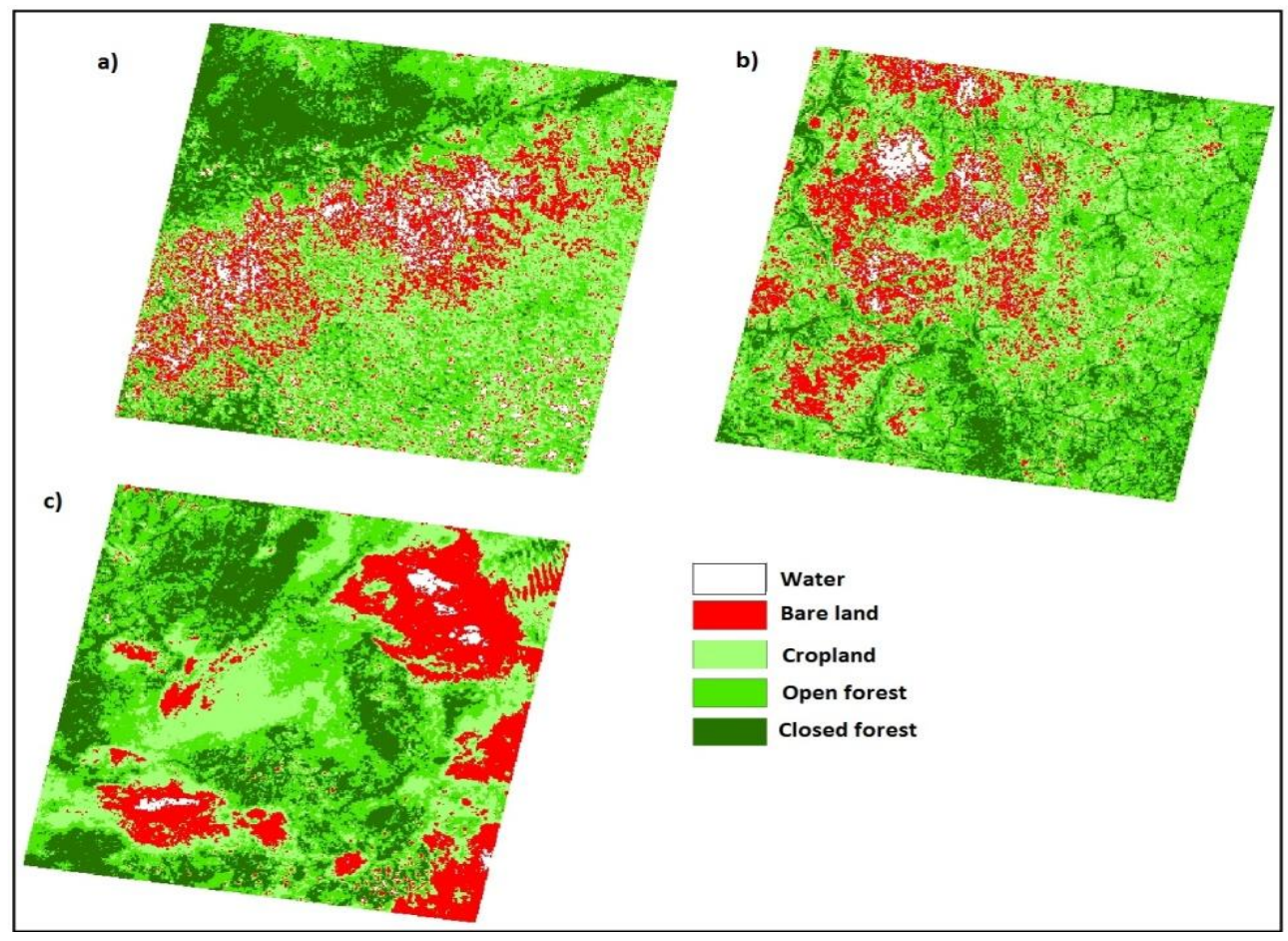

Figure 6 . The vegetation or landcover as given by NDVI values

\subsubsection{NDVI and Flow Accumulation Map}

To better understand the NDVI map especially for areas predicted by the map as water or 
waterlogged area, a flow accumulation (FACC) map (Figure 7) of the study areas were developed which gives the drainage pattern of the areas. This was in a way to help ascertain the accuracy of these predictions. Comparing with the NDVI map (Figure 3), it was observed that regions depicting water were areas on the FACC map where majority of the stream channels seems to be present. From the FACC map, it could be seen that drainage pattern expands randomly at different regions and mostly accumulate at regions of low elevation (see Figure 4, DEM). The more closely the pattern or network, the more water collects and flows in those regions. From this, it was clear why the NDVI map predicted various regions as water especially for a scene taken during wet season.

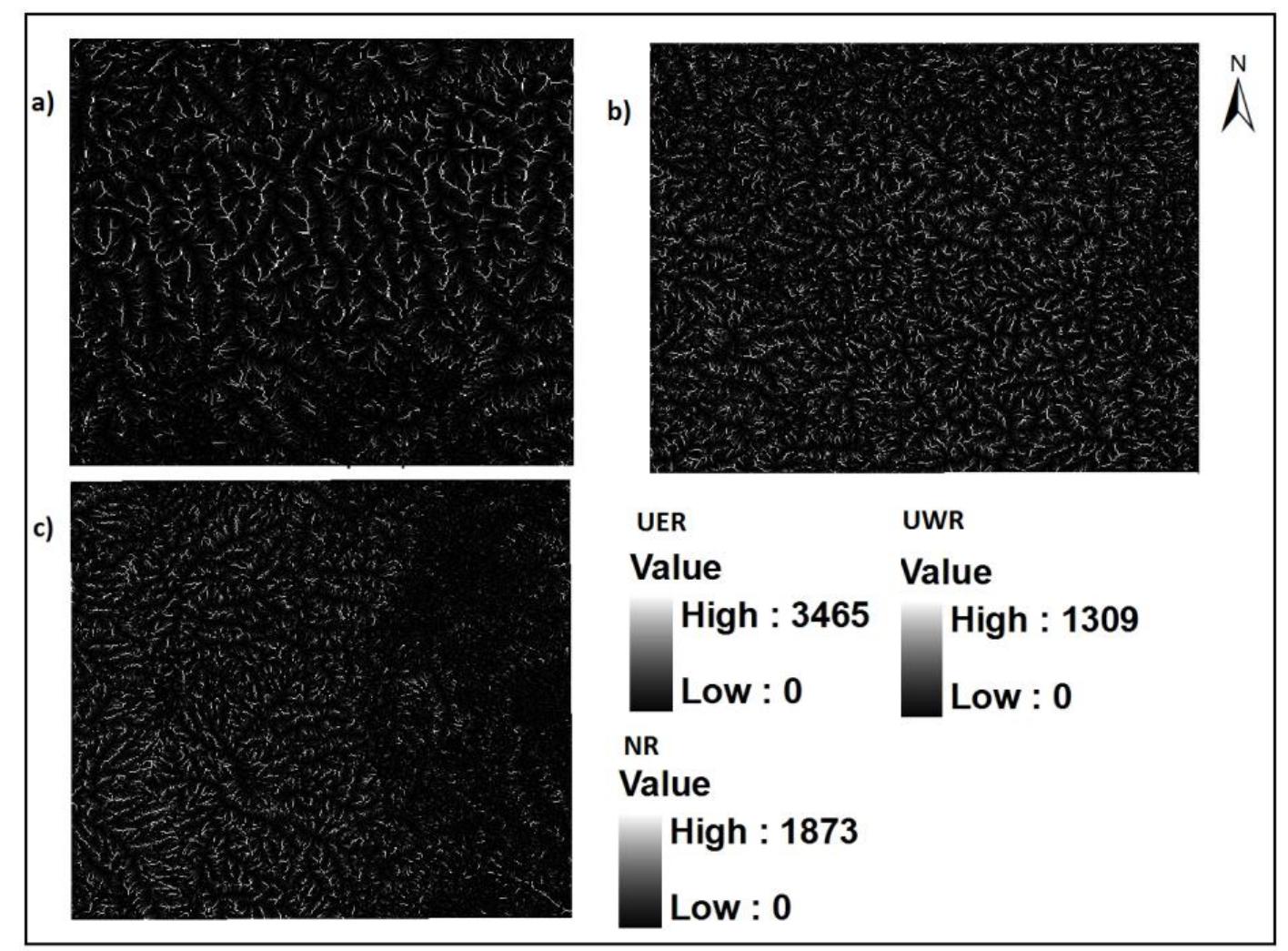

Figure 7. Flow accumulation map of the study areas. a) UER b) UWR c) NR

\section{Conclusion}

The results of this study confirm the utility of NDVI for monitoring the vegetation cover. The study demonstrated that NDVI technique can be employed to evaluate the vegetation cover and hence monitor the environment. At a local scale, mean NDVI values were correlated to vegetation cover types compared to the available LULC map although some uncertainties were observed. However, our results suggest that NDVI can be useful for a general cover monitoring and planning.

\section{Acknowledgement}

The authors are most grateful to the support for this paper by providing the high resolution satellite data provided through project - Planet Action International, Green WaterHut and the 


\section{Ml Macrothink}

Environmental Management and Sustainable Development

ISSN 2164-7682

2013, Vol. 2, No. 1

Department of Environmental Studies Partnership towards an informed understanding of climate variability and impact on small scale irrigation schemes in the Northern Ghana. We would also like to thank critical comments from Prof. Alfred A. Duker, Prof. Yiping Li, Miss Florence Kutin Mensah, Mr. Yaw Nyinaku, Miss Akosua Korantemaa Agadzi and Miss Josephine Kwarteng.

\section{References}

Amiri, F., \& Tayebeh, T. (2009). Operational Monitoring of Vegetative Cover by Remote Sensing in Semi-arid Lands of Iran. Advanced Technology for Cadastre and Land Management, 7th FIG Regional Conference, 1-18

Anim, D.O., Li, Y., Agadzi, A.A., \& Nkrumah, P.A. (2013). Environmental issues of Lake Bosomtwe impact crater in Ghana (West Africa) and its impact on ecotourism potential, International Journal of Scientific \& Engineering Research, 4(1), 1-9.

Anyamba, A., \& Eastman, J. R. (1996). Interannual variability of NDVI over Africa and its relationship to El Nin o/Southern Oscillation. International Journal of Remote Sensing, 17, 2533-2548. http://dx.doi.org/10.1080/01431169608949091

Bannari, A., Morin, D., Bonn F., \& Huete, A. R. (1995). A review of vegetation indices. Remote Sensing Reviews, 13(1), 95-120. http://dx.doi.org/10.1080/02757259509532298

Braimoh, A.K, \& Vlek, P. L.G. (2004). The impact of land-cover change on soil properties in northern Ghana. Land Degradation and Development, 15, 65-74. http://dx.doi.org/10.1002/ldr.590

Deering, D.W \& R.H Haas (1980). NASA Technical Memorandum \# 80727 Greenbelt, MD p21.

Elvidge, C.D. \& Lyon, R. J. P. (1985). Influence of rock-soil spectral variation on the assessment of green biomass. Remote Sensing of Environment, 17, 265-279. http://dx.doi.org/10.1016/0034-4257(85)90099-9

Foody, G M. (2002). Status of Land Cover Classification Accuracy Assessment. Remote Sensing of Environment, 80, 185-201. http://dx.doi.org/10.1016/S0034-4257(01)00295-4

Fung, T., \& Siu, W. (2000). Environmental quality and its changes, an analysis using NDVI, International Journal of Remote Sensing, 21(5), 1011-1024. http://dx.doi.org/10.1080/014311600210407

Global Land Cover Characterization datasets by the U.S. Geological Survey's (USGS) Earth Resources Observation System (EROS) Data Center, the University of Nebraska-Lincoln (UNL) and the Joint Research Center of the European Commission. Available: http://www.landcover.usgs.gov/landcoverdata.php (February 7, 2013)

Gyasi, E.A. (1995). Farming in Northern Ghana. ILEIA Newsletter, 11(4), 23.

Hunt, E.R., \& Rock, B.N. (1989). Detection of changes in leaf water content using near- and middle-infrared reflectances. Remote Sensing of Environment, 30, 43-54. 
http://dx.doi.org/10.1016/0034-4257(89)90046-1

Lyon, J.G., \& McCarthy, J. (1995). Introduction to Wetlands and Environmental Applications of GIS." Wetland and Environmental Applications of GIS. Eds. Boca Raton: CRC Press, Inc., 3-4.

Lyon, J. \& George, T. L. (1979). Vegetation mapping in the Gates of the Arctic National Park. Annual meeting of the American Society of Photogammetry, Vol. II, 484-497.

Maathuis, B., \& Wang, L. (2006). Digital Elevation Model Based Hydro-processing. Geocarto International, 21, 21-26. http://dx.doi.org/10.1080/10106040608542370

Malo, A. R., \& Nicholson, S. E. (1990). A study of rainfall and vegetation dynamics in the African Sahel using Normalized Difference Vegetation Index. Journal of Arid Environments, $19,1-24$.

Marsh, S., Walsh, J., Lee, C., Beck, L., \& Hutchinson, C. (1992). Comparison of multi-temporal NOAA -AV HRR and SPOT-XS satellite data for mapping land-cover dynamics in the West African Sahel. International Journal of Remote Sensing, 13, 2997-3016. http://dx.doi.org/10.1080/01431169208904098

Nartey E., Dowuona G.N., Ahenkorah Y., Mermit A.R, \& Tiesseu H. (1997). Variability in the properties of soils on two toposequence in Northern Ghana. Ghana Journal of Agriculture Science, 30, 115-126

Panda, S.S., Ames, D.P., Panigrahi, S. 2010. Application of vegetation indices for agricultural crop yield prediction using neural network techniques. Remote Sensing, 2, 673-696. http://dx.doi.org/10.3390/rs2030673

Perry, C., Lautenschlager, L. (1984). Functional equivalence of spectral vegetation indices. Remote Sensing of Environment, 14, 169-182. http://dx.doi.org/10.1016/0034-4257(84)90013-0

Poulin, B., Davranche, A., \& Lefebvre, G. (2010). Ecological assessment of Phragmitesaustralis wetlands using multi-season SPOT-5 scenes. Remote Sensing of Environment, 114, 1602-1609. http://dx.doi.org/10.1016/j.rse.2010.02.014

Prince, S. D. 1991. Satellite remote sensing of primary production: comparison of results for Sahelian grassland 1981-1988. International Journal of Remote Sensing, 12, 1301-1312. http://dx.doi.org/10.1080/01431169108929727

Rouse, J. W., Hass, R. W., Schell, J. A., Deering, D. W., \& Harlan, J. C. 1974. Monitoring the vernal advancement and retrogradiation (green wave effect) of natural vegetation. NASA/GSFCT Type III Final Report, Greenbelt, MD, USA.

Schultz, P.A., \& Halpert, M.S. (1993). Global correlation of temperature, NDVI and precipitation. Advances in Space Research, 13(5), 277-280. http://dx.doi.org/10.1016/0273-1177(93)90559-T

Thiam, A. \& Eastman, J. R. (2001). Vegetation indices in IDRISI 3.2 release 2, guide to GIS 


\section{Macrothink \\ Environmental Management and Sustainable Development \\ ISSN 2164-7682 2013, Vol. 2, No. 1}

and image processing. Vol. 2. (Clark University: Worcester, MA.)

Tucker, C. J., Townshend, J. R. G., \& Goff, T. E. (1985). African land-cover classification using satellite data. Science, 227, 369-375. http://dx.doi.org/10.1126/science.227.4685.369

Turner, B.L., Lambin, E.F., \& Reenberg, A. (2007). From the cover land change science special feature: The emergence of land change science for global environmental change and sustainability. Proc. Natl. Assoc. Science, 104, 20666-20671. http://dx.doi.org/10.1073/pnas.0704119104

Vermote, E., Tanre, D., Deuze, J. L., Herman, M., \& Morcrette, J. J. (2006). 6S User Guide Version 3. Available http://loa.univ-lille1.fr/6S/6S_Manual_Part_1.pdf.gz. (February 21, 2013)

Vitousek P. M., Money H. A., Lubchenco J., \& Melillo J. M. (1997). Human domination of Earth's ecosystems. Science, 277, 494-499. http://dx.doi.org/10.1126/science.277.5325.494

Wang J., Rich, P.M., \& Price, K.P. (2003). Temporal responses of NDVI to precipitation and temperature in the central Great Plains, USA. International Journal of Remote Sensing, 24(11), 2345-2364. http://dx.doi.org/10.1080/01431160210154812

Yacouba D., Guangdao, H., \& Xingping, W. (2009). Assessment of Land Use Cover Changes Using NDVI and DEM in Puer and Simao Counties, Yunnan Province, China. World Rural Observations, 1(2), 1-11.

Yang, Y., Yang, L., \& Merchant, J.W. (1997). An assessment of AVHRR/NDVI-ecoclimatological relations in Nebraska, USA. International Journal of Remote Sensing, 18, 2161-2180. http://dx.doi.org/10.1080/014311697217819

\section{Copyright Disclaimer}

Copyright reserved by the author(s).

This article is an open-access article distributed under the terms and conditions of the Creative Commons Attribution license (http://creativecommons.org/licenses/by/3.0/). 